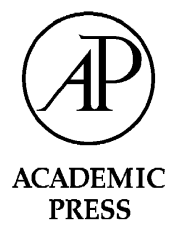

Available online at www.sciencedirect.com

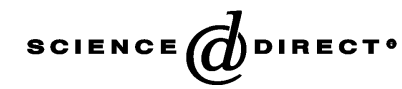

Ecotoxicology

and

Environmental

PRESS

Ecotoxicology and Environmental Safety 54 (2003) 216-222

Safety

http://www.elsevier.com/locate/ecoenv

\title{
Effects of $17 \alpha$-ethinylestradiol on sexual development of the amphipod Hyalella azteca
}

\author{
Gert F. Vandenbergh, ${ }^{\mathrm{a}}$ Dominique Adriaens, ${ }^{\mathrm{b}}$ Tim Verslycke, ${ }^{\mathrm{a}, *}$ and Colin R. Janssen ${ }^{\mathrm{a}}$ \\ ${ }^{a}$ Laboratory of Environmental Toxicology and Aquatic Ecology, Ghent University, J. Pateaustraat 22, 9000 Ghent, Belgium \\ ${ }^{\mathrm{b}}$ Vertebrate Morphology, Ghent University, K.L. Ledeganckstraat 35, 9000 Ghent, Belgium
}

Received 31 July 2001; accepted 7 March 2002

\begin{abstract}
The effects of the synthetic estrogen $17 \alpha$-ethinylestradiol (EE) on sexual development of the freshwater amphipod Hyalella azteca was investigated. Organisms were exposed in a multigeneration experiment to EE concentrations ranging from 0.1 to $10 \mu \mathrm{g} / \mathrm{L}$ and the development of both external and internal sexual characteristics were studied. Second-generation male $H$. azteca exposed from gametogenesis until adulthood to 0.1 and $0.32 \mu \mathrm{g}$ EE/L developed significantly smaller second gnathopods. The sex ratio of the populations exposed to EE for more than two generations tended, although not statistically significantly, to be in favor of females. Histological aberrations of the reproductive tract, i.e., indications of hermaphroditism, disturbed maturation of the germ cells, and disturbed spermatogenesis, of post-F1-generation males were observed in all EE exposures. These findings provide evidence that sexual development of $H$. azteca is affected by exposure to sublethal concentrations of EE.
\end{abstract}

(C) 2002 Elsevier Science (USA). All rights reserved.

Keywords: Endocrine disruption; Invertebrates; Crustaceans; Hyalella azteca; Sexual development; Histology

\section{Introduction}

There has been increasing concern about the potential of anthropogenic chemicals to disrupt the regulation and functioning of the endocrine system of humans and wildlife (IEH, 1999). The majority of the studies that have been done have focused on vertebrate species, whereas invertebrates have received much less attention in this area. An integrated approach to this complicated phenomenon necessitates evaluation of possible endocrine disruptive effects at different taxonomic and trophic levels. The inclusion of invertebrate species in a tiered testing approach for assessing the endocrine disrupting potency of chemicals is therefore required.

Knowledge of the endocrine system of invertebrates is rather limited (except for insect and some crustacean species), although the presence of both vertebrate-type and invertebrate-specific hormones in invertebrates has been demonstrated (Lafont, 2000). Vertebrate-type steroid hormones have been found in several crustacean species, but the physiological role and metabolism are

${ }^{*}$ Corresponding author. Fax: + 32-9-264-3766.

E-mail address: tim.verslycke@rug.ac.be (T. Verslycke). not fully understood (Fairs et al., 1989; Jeng et al., 1978; Novak et al., 1990). Sexual differentiation in malacostracan crustaceans, such as amphipods, is regulated by the androgenic gland (AG). In males, the primordial AGs develop and synthesize the androgenic gland hormone (AGH), which induces male sexual differentiation. In females, however, the primordial AGs do not develop and female sexual differentiation is induced spontaneously (Charniaux-Cotton, 1960; Hasegawa et al., 1993).

The best known example of environmental endocrine disruption in invertebrates is the tributyltin-induced development of imposex in marine female gastropods (Bryan et al., 1988; Gibbs et al., 1991). Masculinization of clams (Ruditapes decussata) was observed after transplantation from a relatively clean area to an organotin-polluted marina (Morcillo and Porte, 2000). Effects of (possible) endocrine disruption as a consequence of exposure to anthropogenic substances have also been reported in several crustacean species. Moore and Stevenson (1991) noted abnormal sex ratios in harpacticoid copepods collected in the vicinity of sewage discharges, and Sundelin and Eriksson (1998) found an increased incidence of embryonic malformations in the 
amphipod Monoporeia affinis originating from sites receiving industrial effluents. Inhibition of barnacle settlement and induction of cypris major protein in barnacle larvae have been reported after exposure to the xeno-estrogen 4-nonylphenol and the natural estrogen $17 \beta$-estradiol (Billinghurst et al., 1998, 2000). Increased antenna length has been observed in Corophium volutator amphipods exposed to 4-nonylphenol (Brown et al., 1999) and Andersen et al. (1999) reported the stimulation of ovarian maturation in the copepod Acartia tonsa after exposure to $17 \beta$-estradiol and the xeno-estrogen bisphenol A. In Daphnia magna, disturbances in testosterone metabolism and the development of secondary sex characteristics occurred after exposure to different endocrine active substances (Baldwin and LeBlanc, 1994; Baldwin et al., 1995, 1997; Olmstead and LeBlanc, 2000).

In the present study, the effect of sublethal concentrations of the synthetic estrogen $17 \alpha$-ethinylestradiol (EE) on the sexual development of the freshwater amphipod Hyalella azteca was investigated. As $H$. azteca represents a primary food source for fish, birds, amphibians, and other invertebrates and is commonly used as test species in standardized (sediment) toxicity tests, it can be considered ecologically relevant for use as a sentinel species for the evaluation of environmental endocrine disruption.

\section{Materials and methods}

\subsection{Culture of organisms}

Initial cultures of $H$. azteca were obtained in 1993 from Aqua Survey Ltd. Stock cultures have been maintained in 200-L glass aquaria containing tap water at $25^{\circ} \mathrm{C}$ and a light regime of $16 \mathrm{~L} / 8 \mathrm{D}$ has been used. The organisms are fed rabbit pellets ad libitum three times weekly. Since 1998, two subcultures have been initiated using carbon-filtered tap water as culture medium. The carbon-filtered tap water is used to prevent possible contamination of the culture medium.

\subsection{Stock solutions}

Stock solutions of EE (Sigma Aldrich, Bornem, Belgium) were prepared by dissolving $1 \mathrm{~g} / \mathrm{L}$ of $\mathrm{EE}$ in ethanol (p.a.). Test solutions were prepared by serial dilution of the stock using carbon-filtered tap water.

\subsection{Experimental design}

As no $H$. azteca toxicity data for EE were available in the literature, a range-finding test was performed to determine a sublethal concentration range. Per replica, five precopulatory pairs were exposed to nominal concentrations ranging from $0.1 \mu \mathrm{g}$ to $1 \mathrm{mg} \mathrm{EE} / \mathrm{L}$ in 1.5-L glass beakers for 10 days. Each treatment consisted of three replicas. A control using carbonfiltered tap water and a solvent control $(0.01 \%$ ethanol $)$ were also tested. Other exposure conditions were $25^{\circ} \mathrm{C}$ and a light:dark cycle of 16:8 $\mathrm{h}$. The exposure medium was renewed every 2 days.

Based on the results of the range finding test, concentrations of $0.1,0.32,1,3.2$, and $10 \mu \mathrm{g} \mathrm{EE} / \mathrm{L}$ and a solvent control (maximum $0.0001 \%$ ethanol) were selected for further experiments. In addition to the multigeneration toxicity test, a one-generation test was performed to evaluate the effect of the selected EE concentrations on mortality. The experimental setup of the one-generation toxicity test was similar to that of the range-finding test, except that four replicas and an exposure period of 14 days were used. The multigeneration toxicity test was performed in $20-\mathrm{L}$ glass aquaria at a temperature of $25^{\circ} \mathrm{C}$ and using a $L / D$ cycle of $16: 8 \mathrm{~h}$. At the start of the experiment, 150 precopulatory pairs were added to each treatment $(P$ generation). Twice a week, the exposure media were renewed and the organisms were fed rabbit pellets ad libitum. The first offspring of the $P$ generation, which appeared after 2 weeks, were discarded because it was not sure whether they had developed during the EE exposure. After 4 weeks of exposure, juveniles (F1 generation) were isolated and cultured until maturity under the same experimental conditions as the $P$ generation. Additionally, 10 male and female $P$-generation organisms were fixed in sucrose formol for length measurements of both antennas and the male second gnathopods. Length measurements were performed using the image processing program SigmaScan (Jandel Scientific Software, Chicago, IL) and the results were normalized to the body length of the organisms by expressing the length of the appendices relative to the total body length. At maturity, 10 male and female F1 organisms were also fixed for length measurements. After 10 weeks, juveniles of the F2 generation were isolated and cultured under the same experimental conditions for an additional 25 weeks, allowing the development of a stable population from which adult organisms were isolated for histological analysis. The remaining organisms were collected and sexed to evaluate the effect of EE exposure on the sex ratio. Chemical analysis of the exposure media used in the multigeneration experiment was performed according to Böhmer and Kurzawa (2001), whereas nominal concentrations were used in the one-generation toxicity test.

\subsection{Histological analysis}

After 35 weeks of exposure, 5-10 randomly selected male $H$. azteca (post-F1 generation) were fixed in a solution of ethanol:formaldehyde:acetic acid (75:20:5 
$\mathrm{v} / \mathrm{v})$. The organisms were subsequently rinsed with tap water, dehydrated in successive ethanol solutions, and finally embedded in Technovit 7100 (Heraeus Kulzer, Wehrheim, Germany). Serial sections $(5 \mu \mathrm{m})$ were cut and stained with toluidin blue. The sections were analyzed visually by light microscopy.

\subsection{Statistical analysis}

Mortality data and length measurements were tested for normality and variance homogeneity using probability plots and Levene's test, respectively, and are expressed as means \pm standard deviations. One-way ANOVA followed by Duncan's multiple-range test was performed to determine significant differences. Variations in the sex ratio were evaluated using the observed vs expected chi-square test (Statistica, Statsoft, Inc., Tulsa, OK). Significance was established at $P<0.05$.

\section{Results}

The measured concentrations in the multigeneration toxicity test were within $15 \%$ of the nominal concentrations, except for the $0.1 \mu \mathrm{g} \mathrm{EE} / \mathrm{L}$ treatment where the actual concentration was $0.023 \mu \mathrm{g} \mathrm{EE} / \mathrm{L}$.

Significant mortality of respectively $53 \%$ and $40 \%$ was observed after exposure to 0.1 and $1 \mathrm{mg} \mathrm{EE} / \mathrm{L}$ for 10 days (range finding test). During the 14-day onegeneration toxicity test, no significant mortality was observed in any of the treatments. A maximum mortality of $13 \%$ was noted in the $3.2 \mu \mathrm{g} / \mathrm{L}$ exposure groups. It was therefore assumed that no significant mortality occurred in the multigeneration toxicity test.

The normalized length of antenna 1 and 2 of exposed $P$-generation organisms ranged from 0.427 to 0.460 and 0.550 to 0.608 for males and 0.399 to 0.425 and 0.506 to 0.542 for females, respectively, and was not statistically significant from those in the controls $(0.421$ and 0.556 for males and 0.375 and 0.493 for females, respectively). Also, in the $P$ generation no effects were seen on the normalized length of the male second gnathopods $(0.257-0.286)$ compared to the controls $(0.271)$. In the $\mathrm{F} 1$ generation, males exposed to 0.1 and $0.32 \mu \mathrm{g} \mathrm{EE} / \mathrm{L}$ developed significantly smaller second gnathopods ( 0.255 and 0.259 , respectively) compared to the controls (0.309). The length of the second gnathopods of F1 males exposed to the higher concentrations ranged from 0.287 to 0.294 , which was not statistically different from the controls. No significant effects were observed on the growth and development of antenna 1 and 2 of male (0.444-0.468 and 0.584-0.614, respectively) and female (0.388-0.426 and 0.493-0.529, respectively) F1-generation organisms (Fig. 1).
Exposure to $0.1-10 \mu \mathrm{g} \mathrm{EE} / \mathrm{L}$ during the complete life span of the organisms (gametogenesis to adulthood) did not lead to significant changes in the sex ratio of post-F1 organisms (Table 1). However, an increased occurrence of females relative to males with increasing $\mathrm{EE}$ concentrations was observed, reaching a maximum in the range $0.32-3.2 \mu \mathrm{g} \mathrm{EE} / \mathrm{L}$. At $10 \mu \mathrm{g} \mathrm{EE} / \mathrm{L}$ the number of females decreased below that of the control level. Moreover, it should be noted that using the observed vs expected chi-square test with an equal male-female expectancy, significantly more females were observed in all concentrations including the control.

Cellular abnormalities in the reproductive system of male $H$. azteca exposed to EE (all concentrations) were observed. Larger and more spherical germ cells (1), a hollow cell structure (2), and less dense cytoplasm (3), analogous to female gonad morphology, were observed in male $H$. azteca exposed to $0.32,1,3.2$, and $10 \mu \mathrm{g} \mathrm{EE} /$ L (Figs. 2A and B). The staining of the nuclei of the germ cells was more intense and oocyte-like structures were clearly distinguished in males exposed to $0.32,3.2$, and $10 \mu \mathrm{g} \mathrm{EE} / \mathrm{L}$ (Fig. 2C). Spermatids were smaller (Fig. 3), and in the vas deferens fewer and irregular shaped spermatozoa were noted after exposure to $10 \mu \mathrm{g}$ EE/L (Fig. 4).

\section{Discussion}

Sexual differentiation in malacostracan crustaceans, such as $H$. azteca, is determined by the AGH secreted by the AG. AGH is essential for the development of the male primary and secondary sex characteristics, i.e. differentiation of the testes, spermatogenesis, differentiation of the sperm duct primordia, growth of the secondary sex characteristics, and male sexual behavior. However, the regulation of the synthesis and mechanisms of action of the AGH is not fully understood (Charniaux-Cotton, 1960; Hasegawa et al., 1993). As EE may affect the development of secondary sex characteristics of $H$. azteca as a consequence of a general growth effect, the relative relationship between the length of the secondary sex characteristics and the total body length of male and female $H$. azteca eliminates a possible general growth effect of EE. Deviations from this relationship indicate a specific effect on the development of the respective sexual characteristic. Organisms from the $P$ generation were exposed after the period of sexual differentiation. As expected, no effects were observed on the normalized length of the first and second antennas or the male second gnathopods. However, F1 males exposed to 0.1 and $0.32 \mu \mathrm{g} \mathrm{EE} / \mathrm{L}$ during their complete life span (gametogenesis until adulthood) developed significantly smaller second gnathopods. At higher concentrations of EE, the size of the male second gnathopods was smaller than those of the controls (not 

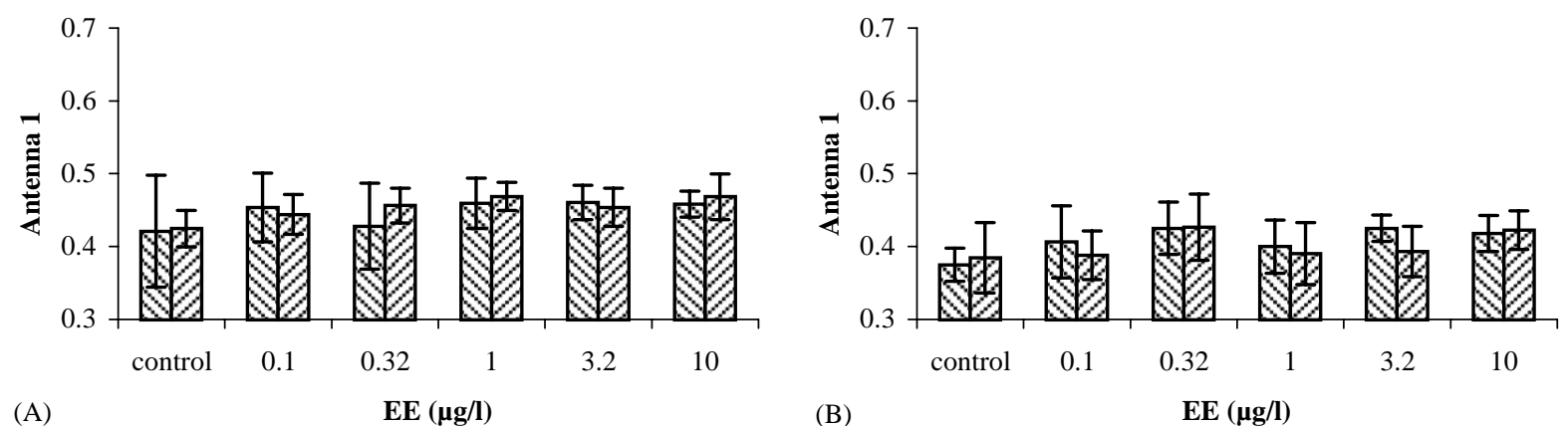

(B)

EE $(\mu \mathrm{g} / \mathrm{l})$
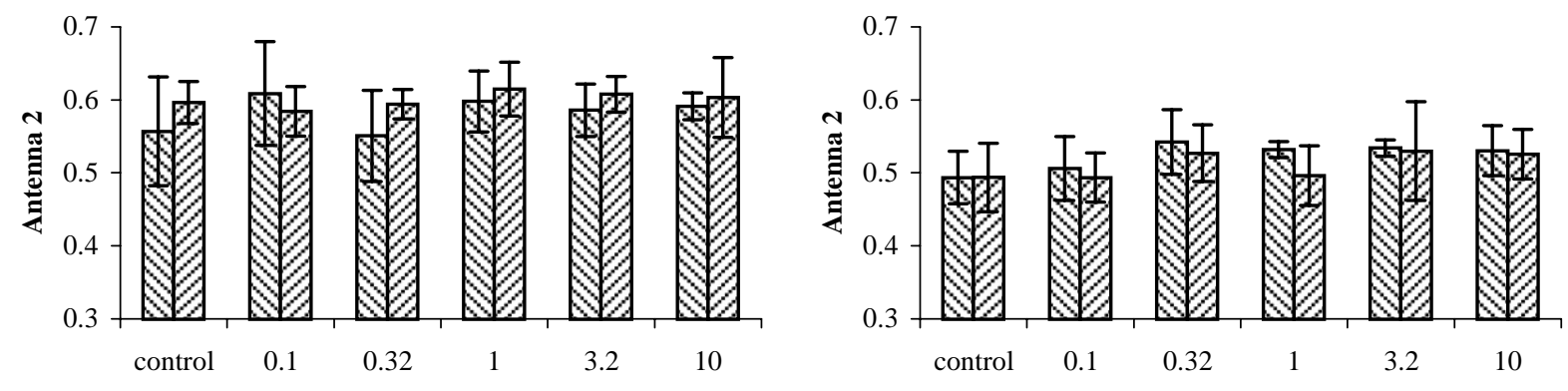

(C)

EE $(\mu \mathrm{g} / \mathrm{l})$

(D)

$\mathrm{EE}(\mu \mathrm{g} / \mathrm{l})$

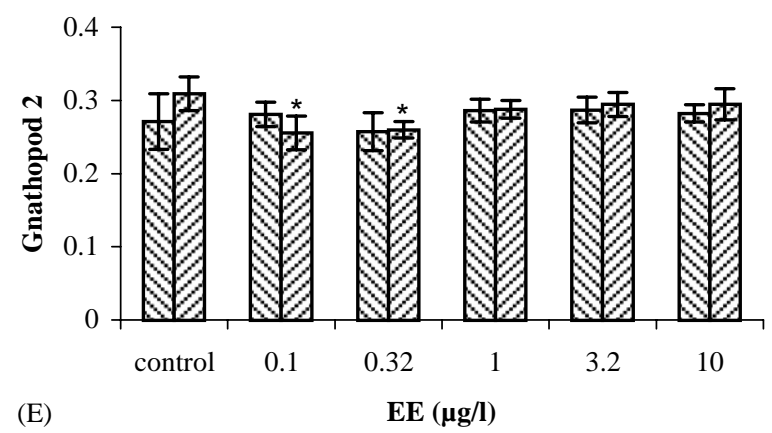

Fig. 1. Normalized length of antenna 1 of male (A) and female (B), antenna 2 of male (C) and female (D), and the second gnathopod of male (E) $H$. azteca exposed to EE (left bars, $P$ generation; right bars, F1 generation; ${ }^{*} P<0.05$ ).

Table 1

Sex ratio of post-F1-generation $H$. azteca exposed to EE

\begin{tabular}{lllll}
\hline Concentration $(\mu \mathrm{g} / \mathrm{L})$ & $n$ & Females $(\%)$ & Males $(\%)$ & Ratio F/M \\
\hline Control & 300 & 55 & 45 & 1.22 \\
0.1 & 268 & 56.3 & 43.7 & 1.29 \\
0.32 & 186 & 57.5 & 42.5 & 1.35 \\
1 & 349 & 57.3 & 42.7 & 1.34 \\
3.2 & 241 & 58.5 & 41.5 & 1.41 \\
10 & 352 & 53.1 & 46.9 & 1.13 \\
\hline
\end{tabular}

significant) but larger than those of organisms exposed to 0.1 and $0.32 \mu \mathrm{g} \mathrm{EE} / \mathrm{L}$. These findings suggest a receptor-mediated response where effects are observed at lower (intermediate) concentrations and masked at higher concentrations (U-shaped dose response). Possibly, these effects are induced by interaction of EE with the (putative) $\mathrm{AH}$ receptor or the ecdysteroid receptor. Likewise, Baldwin et al. (1995) hypothesized that diethylstilbestrol-induced molting effects in $D$. magna may be elicited through interaction with the ecdysteroid receptor. On the other hand, EE may have affected AGH activity via direct disruption of the $A G$, direct interaction with the $\mathrm{AGH}$, or interaction with hormonemetabolizing enzymes. In the amphipod Orchestia gammarellus, implantation of the AG induces masculinization of the primary and secondary sex characteristics of immature and mature females. Conversely, after ablation of the AG from males the development of the male sex characteristics was inhibited. Moreover, after amputation of the second gnatopods of male $O$. gammarellus regeneration occurs into the female form (Charniaux-Cotton, 1960). Also, masculinization of females of the isopod Armadillidium vulgare was 


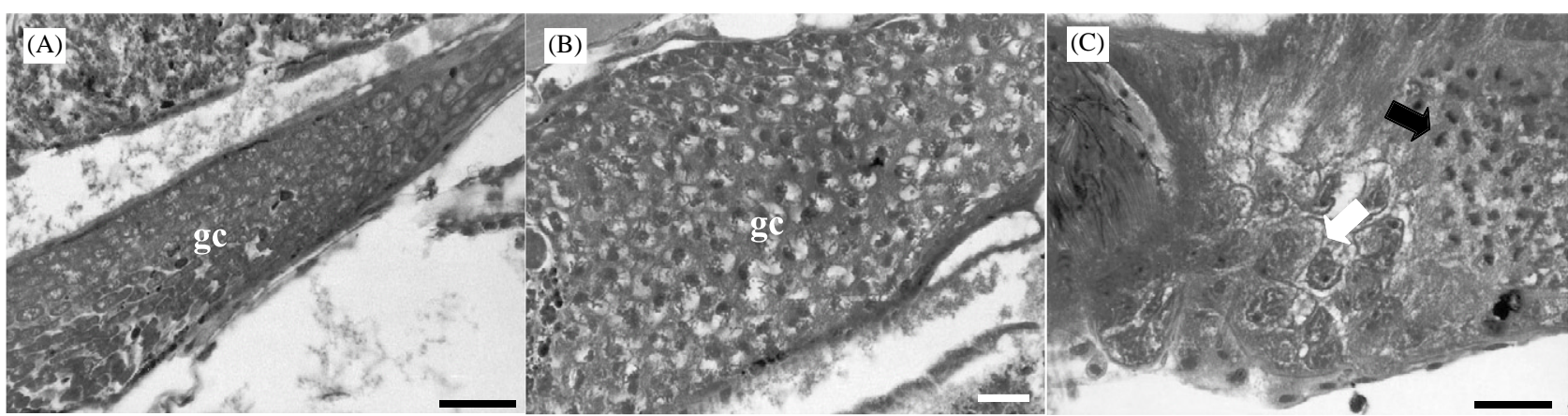

Fig. 2. Section of the reproductive tract of post-F2-generation male H. azteca exposed to EE: (A) control; (B) $3.2 \mu \mathrm{g} / \mathrm{L}$; and (C) $3.2 \mu \mathrm{g} / \mathrm{L}$ (white arrow, oocyte-like structures; black arrow, intensely stained nuclei of germ cells) (gc, germ cells; bar, $100 \mu \mathrm{m})$.

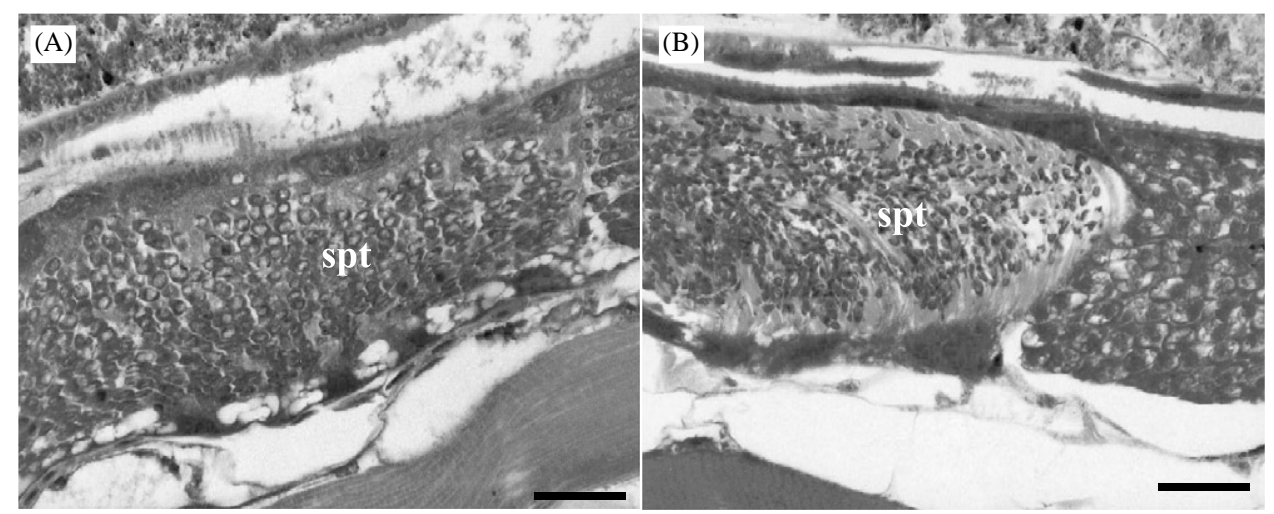

Fig. 3. Section of the reproductive tract of post-F2-generation male H. azteca exposed to EE: (A) control and (B) $10 \mu \mathrm{g} / \mathrm{L}$ (spt, spermatids; bar, $100 \mu \mathrm{m})$.

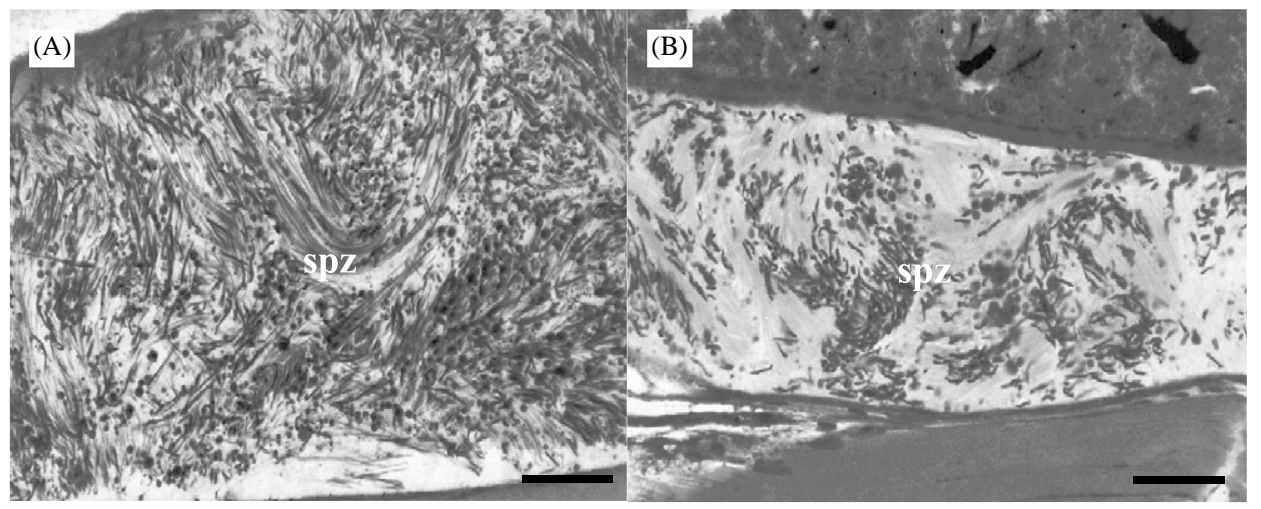

Fig. 4. Section of the vas deferens of post-F2-generation male H. azteca exposed to EE: (A) control and (B) $10 \mu \mathrm{g} / \mathrm{L}$ (spz, spermatozoa; bar, $100 \mu \mathrm{m}$ ).

observed following injections of an active extract of the AG (Katakura and Hasegawa, 1983). The development of smaller second gnatopods of male $H$. azteca could be a reproductive disadvantage because the second gnathopods are used to grip the female partner during copulation. As mentioned, no effect on the length of antennas 1 and 2 was observed in the present study. Brown et al. (1999), on the other hand, reported an increased length of the second antenna of $C$. volutator exposed to the estrogenic chemical 4-nonylphenol. In $D$. magna, the development of female secondary sex characteristics was enhanced by exposure to the synthetic estrogen diethylstilbestrol and the juvenile hormone analog methoprene, whereas male secondary characteristics were induced after exposure to the androgen androstenedione (Olmstead and LeBlanc, 2000).

The sex ratio of $H$. azteca populations exposed to $0.1-$ $10 \mu \mathrm{g} \mathrm{EE} / \mathrm{L}$ was not statistically significantly affected, although the number of females increased with increasing EE concentrations, reaching a maximum in the range $0.32-3.2 \mu \mathrm{g} \mathrm{EE} / \mathrm{L}$. As no data on the natural variation of the sex ratio of $H$. azteca are available, firm conclusions cannot be drawn. In nature, skewed sex 
ratios in favor of females were observed in copepod populations collected at sites receiving sewage discharges (Moore and Stevenson, 1991, 1994). Dodson and Hanazato (1995) reported a dramatic decrease in the relative number of males in some Daphnia sp. populations and suggested that this may be correlated with anthropogenic pollution. Masculinization of $R$. decussata was observed after exposure to tributyltin (Morcillo and Porte, 2000). In contrast, Bechmann (1999) and Hutchinson et al. (1999) reported no effects on sex ratio, development, or reproduction of the marine copepod Tisbe battagliai after exposure to EE, $17 \beta$-estradiol, estrone, and 4-nonylphenol.

Histological analysis of the reproductive tract of male $H$. azteca indicates that cellular abnormalities occurred in the post-F1 generations after exposure to $\mathrm{EE}$ concentrations ranging from 0.1 to $10 \mu \mathrm{g} / \mathrm{L}$. These observations indicate some degree of hermaphroditism and disrupted germination of germ cells and spermatozoa development. As for the effects on the male secondary sex characteristics, more pronounced effects were observed at lower concentrations (0.32-3.2 $\mu \mathrm{g} \mathrm{EE/}$ L) compared to the highest exposure groups $(10 \mu \mathrm{g} \mathrm{EE} /$ L). Again, these findings suggest a receptor-mediated response. As mentioned above, a disturbed functioning of the $\mathrm{AG}$ through exposure to $\mathrm{EE}$ or a direct interaction of EE with the AGH or hormone-metabolizing enzymes and subsequent changes in AGH activity may also be possible. In crustaceans, the occurrence of various degrees of intersex has been described for different species, e.g. the isopods Porcellio dilatatus, Porcellio maculates, and Porcellionides pruinosus; the amphipods Talitrus saltator, O. gammarellus, O. mediterranea, Jassa falcate, and Gammarus chevreuxi (for a review, see Charniaux-Cotton, 1960). It has been suggested that a disruption of $\mathrm{AG}$ function and/or AGH activity may be responsible for this phenomenon. As no histological signs of intersex were observed in the controls, the observed effects should be attributed to the EE exposure.

The ecological significance of the observed effects and the mechanisms of action of possible endocrine disruption remain to be investigated. In future research, the development and reproduction of $H$. azteca exposed to lower, environmentally realistic concentrations of endocrine disrupting substances will be studied.

\section{Conclusions}

Uncertainties about the regulation and functioning of the endocrine system of many invertebrate species hamper applied research on the effects of endocrine disruptors on invertebrates. This study provides evidence that sexual development of the amphipod $H$. azteca may be affected by exposure to sublethal concentrations of the synthetic estrogen EE. The development of male secondary sex characteristics was repressed and the sex ratio tended to be in favor of female development. Besides the external sex characteristics, the morphology of the reproductive tract was also affected by EE. Indications of hermaphroditism and disturbed maturation of the germ cells and spermatogenesis were observed in male $H$. azteca exposed to EE concentrations ranging from 0.1 to $10 \mu \mathrm{g} \mathrm{EE} / \mathrm{L}$. The effects were more pronounced at lower (intermediate) concentrations, which suggests that they are receptormediated responses. It should be noted, however, that the test concentrations used in the current study are substantially higher than those reported to affect vertebrates and those observed in natural environments.

\section{Acknowledgments}

This study was financially supported by the European Commission, Contract ENV4-CT97-0509. The authors thank Gertie De Neve for expert technical assistance.

\section{References}

Andersen, H.R., Halling-Sørensen, B., Kusk, K.O., 1999. A parameter for detecting estrogenic exposure in the copepod Acartia tonsa. Ecotoxicol. Environ. Saf. 44, 56-61, doi: eesa.1999.1800.

Baldwin, W.S., LeBlanc, G.A., 1994. Identification of multiple steroid hydroxylases in Daphnia magna and their modulation by xenobiotics. Environ. Toxicol. Chem. 13, 1013-1021.

Baldwin, W.S., Milam, D.L., LeBlanc, G.A., 1995. Physiological and biochemical perturbations in Daphnia magna following exposure to the model environmental estrogen diethylstilbestrol. Environ. Toxicol. Chem. 14, 945-952.

Baldwin, W.S., Graham, S.E., Shea, D., LeBlanc, G.A., 1997. Metabolic androgenization of female Daphnia magna by the xenoestrogen 4-nonylphenol. Environ. Toxicol. Chem. 16, 19051911.

Bechmann, R.K., 1999. Effect of the endocrine disrupter nonylphenol on the marine copepod Tisbe battagliai. Sci. Total Environ. 233, 33-46.

Billinghurst, Z., Clare, A.S., Fileman, T., McEvoy, J., Readman, J., Depledge, M.H., 1998. Inhibition of barnacle settlement by the environmental oestrogen 4-nonylphenol and the natural oestrogen $17 \beta$ oestradiol. Mar. Pollut. Bull. 36, 833-839.

Billinghurst, Z., Clare, A.S., Matsumura, K., Depledge, M.H., 2000. Induction of cypris major protein in barnacle larvae by exposure to 4-n-nonylphenol and 17 $\beta$-estradiol. Aquat. Toxicol. 47, 203-212.

Böhmer, W., Kurzawa, B., 2001. Bestimmung von $17 \alpha$-ethinylestradiol mittels GC/MS/MS nach SPE-extraktion an EMPORE disks. GIT Labor-Fachzeitschrift 1, 57-59.

Brown, R.J., Conradi, M., Depledge, M.H., 1999. Long-term exposure to 4-nonylphenol affects sexual differentiation and growth of the amphipod Corophium volutator (Pallas, 1766). Sci. Total Environ. 233, 77-88.

Bryan, G.W., Burt, G.R., Gibbs, P.E., 1988. A comparison of the effectiveness of tri- $n$-butylchloride and five other organotin compounds in promoting the development of imposex in the dogwhelk, Nucella lapillus. J. Mar. Biol. Assoc. UK 68, 733-744. 
Charniaux-Cotton, H., 1960. Sex determination. In: Waterman, T.H. (Ed.), The Physiology of Crustacea, Vol. I, Metabolism and Growth. Academic Press, New York and London, pp. 411-447.

Dodson, S.I., Hanazato, T., 1995. Commentary on effects of anthropogenic and natural organic chemicals on development, swimming behavior, and reproduction of Daphnia, a key member of aquatic ecosystems. Environ. Health Perspect. 103 (Suppl. 4), $7-11$.

Fairs, N.J., Evershed, R.P., Quinlan, P.T., Goad, L.J., 1989. Detection of unconjugated and conjugated steroids in the ovary, eggs, and haemolymph of the decapod crustacean Nephrops norvegicus. Gen. Comp. Endocrinol. 74, 199-208.

Gibbs, P.E., Bryan, G.W., Pascoe, P.L., 1991. Tributyltin-induced imposex in stenoglossan gastropods: pathological effects on the female reproductive system. Comp. Biochem. Physiol. C 100, 231235.

Hasegawa, Y., Hirose, E., Katakura, Y., 1993. Hormonal control of sexual differentiation and reproduction in crustacea. Am. Zool. 33, 403-411.

Hutchinson, T.H., Pounds, N.A., Hampel, M., Williams, T.D., 1999. Impact of natural and synthetic steroids on the survival, development and reproduction of marine copepods (Tisbe battagliai). Sci. Total Environ. 233, 167-179.

IEH, 1999. IEH assessment on the ecological significance of endocrine disruption: effects on reproductive function and consequences for natural populations. Assessment A4, MRC Institute for Environment and Health, Leicester, UK.
Jeng, S.S., Wan, W.C., Chang, C.F., 1978. Existence of an estrogenlike compound in the ovary of the shrimp Parapenaeus fissures. Gen. Comp. Endocrinol. 36, 211-214.

Katakura, Y., Hasegawa, Y., 1983. Masculinization of females of the isopod crustacean, Armadillidium vulgare, following injections of an active extract of the androgenic gland. Gen. Comp. Endocrinol. 48, 57-62.

LaFont, R., 2000. The endocrinology of invertebrates. Ecotoxicology 9, 41-57.

Moore, C.G., Stevenson, J.M., 1991. The occurrence of intersexuality in harpacticoid copepods and its relationship with pollution. Mar. Pollut. Bull. 22, 72-74.

Moore, C.G., Stevenson, J.M., 1994. Intersexuality in benthic harpacticoid copepods in the Firth of Forth, Scotland. J. Nat. Hist. 28, 1213-1230.

Morcillo, Y., Porte, C., 2000. Evidence of endocrine disruption in clams - Ruditapes decussata - transplanted to a tributyltin-polluted environment. Environ. Pollut. 107, 47-52.

Novak, F., Van Beek, E., Lambert, J., De Loof, A., 1990. Pregnenolone and estradiol identification in the brine shrimp, Artemia sp., by means of gas chromatographical-mass spectrometrical analysis. Comp. Biochem. Physiol. B 95, 565-569.

Olmstead, A.W., LeBlanc, G.A., 2000. Effects of endocrine-active chemicals on the development of sex characteristics of Daphnia magna. Environ. Toxicol. Chem. 19, 2107-2113.

Sundelin, B., Eriksson, A.K., 1998. Malformations in embryos of the deposit-feeding amphipod Monoporeia affinis in the Baltic Sea. Mar. Ecol. Prog. Ser. 171, 165-180. 